\title{
Experiência docente com bebês: \\ um olhar a partir da educação física
}

\section{Teaching experiences with toddlers:}

a physical education perspective

\section{Experiencia docente con bebés:}

una mirada desde la educación física

DANIEL TORRES VILARINO*

Universidade do Estado de Santa Catarina, Florianópolis- SC, Brasil.

ANDERSON SIMAS FRUTUOSO*

Sec. Municipal de Educação de São José, São José- SC, Brasil.

JULIANA DE PAULA FIGUEIREDO

Universidade do Estado de Santa Catarina, Florianópolis- SC, Brasil.

VIVIANE PREICHARDT DUEK

Universidade do Estado de Santa Catarina, Florianópolis- SC, Brasil.

\begin{abstract}
RESUMO: $\mathrm{O}$ artigo apresenta reflexões sobre a docência com bebês no estágio curricular supervisionado em educação física na educação infantil. A experiência indicou a importância da organização do espaço para a promoção da autonomia e segurança dos bebês, bem como do emprego de diferentes linguagens, valorizando as relações do bebê com o meio, com os objetos e com os pares. Conclui-se que a educação física, integrada à proposta da instituição, deve considerar
\end{abstract}

\footnotetext{
* Licenciado em Educação Física pela Universidade do Estado de Santa Catarina. E-mail: $<$ daniel_0863@hotmail.com>.

* Mestre em Educação Física pela Universidade Federal de Santa Catarina. Professor da Educação Infantil na Rede Municipal de São José-SC. E-mail: <anderson.frutuoso@outlook.com>.

*** Doutora em Educação Física pela Universidade Federal de Santa Catarina. Professora da Universidade do Estado de Santa Catarina. E-mail: <julianapfig@hotmail.com>.

**** Doutora em Educação pela Universidade Federal do Rio Grande do Norte. Professora da Universidade do Estado de Santa Catarina. E-mail:<vividuek@hotmail.com>.
} 
as características, necessidades e interesses dos bebês, a fim de contribuir para a ampliação do repertório motor, cultural e social.

Palavras-chave: Educação física. Educação infantil. Bebês. Estágio curricular supervisionado. Creche.

ABSTRACT: This article introduces reflections in the teaching experience with toddlers, under the curricular supervised internship in physical education, in early childhood education. The experience pointed out the importance of organizing the spaces in a way to promote the autonomy and safety of toddlers, valuing the toddler's relationship with the environment, with the objects, and with peers. We have concluded that physical education, integrated with the institution's proposals, must consider the characteristics, needs, and interests of toddlers, in order to contribute to the expansion of their motor coordination repertoire.

Keywords: Physical education. Early childhood education. Toddlers. Supervised curricular internship. Nursery school.

RESUMEN: El artículo presenta reflexiones sobre la enseñanza a bebés en una pasantía curricular supervisada de educación física en la educación infantil. La experiencia señaló la importancia de organizar el espacio para promover la autonomía y seguridad de los bebés, así como el uso de diferentes lenguajes, valorando las relaciones del bebé con el entorno, con los objetos y con los compañeros. Se concluye que la educación física, integrada a la propuesta de la institución, debe considerar las características, necesidades e intereses de los bebés, con el fin de contribuir a la ampliación del repertorio motriz, cultural y social.

Palabras clave: Educación Física. Educación Infantil. Bebés. Pasantía supervisada. Guardería.

\section{Introdução}

I nicialmente, a oferta da educação infantil (EI) no Brasil assumiu um caráter assistencialista e, mais recentemente, um viés eminentemente pedagógico, com vistas à formação global da criança (KUHLMANNJUNIOR, 2000). Nesse contexto, a EI surge como direito da criança, assegurado pela Constituição Federal (BRASIL, 1988) e pela Lei de Diretrizes e Bases da Educação Nacional (Lei 9394/96), que reconhecem creches e pré-escolas 
como a primeira etapa da educação básica, visando o desenvolvimento integral da criança de zero a cinco anos de idade, em seus aspectos físico, psicológico e cognitivo (BRASIL, 1996).

A EI apresenta aspectos únicos, sendo compreendida como um espaço/tempo socioeducativo, responsável por ampliar e diversificar as vivências e conhecimentos das crianças, concebidas enquanto sujeitos concretos e reais, situados em contextos sociais e culturais que as constituem. Nessa ótica, esta etapa educacional não pode ser pensada como preparatória para o ensino fundamental e nem ter seus objetivos assim pautados (ROCHA; GIRARDI; BUSS-SIMÃO, 2014).

No tocante à educação física (EF), a legislação assegura que ela é parte indissociável do currículo, devendo estar integrada à proposta pedagógica da instituição (BRASIL, 1996). Na rede municipal de ensino de Florianópolis, a EF está inserida nas creches e Núcleos de Educação Infantil (Neim) ${ }^{1}$ desde 1982. Ao longo desse percurso, diferentes perspectivas teórico-metodológicas ofereceram suporte para a EF direcionada à EI do município, em particular aquelas oriundas dos referenciais da psicomotricidade, da recreação e da aprendizagem motora, apresentando um caráter compensatório, preparatório e instrumental (SAYÃO, 1996).

Nesse cenário, o debate acerca da especificidade da EF, seu papel e sua importância para a formação da pequena infância, vem se ampliando nas últimas décadas. Dentre outros aspectos, discute-se a possibilidade de um projeto pedagógico na EI que supere o modelo "escolarizado" que, ao organizar os conteúdos em disciplinas, fragmenta o conhecimento e demarca o tempo de trabalho, desconsiderando as características das crianças, bem como as especificidades do currículo da EI (AYOUB, 2001; VIEIRA; MEDEIROS, 2007).

Nessa lógica, a EF no interior da EI, não pode ser pensada com tempos e espaços compartimentados e pré-determinados, devendo preocupar-se em ampliar conhecimentos, linguagens, interações e leitura de mundo por parte das crianças, a fim de que desempenhem um papel ativo em seus movimentos. Portanto, mais que propor um conjunto de atividades para ocupar as crianças, o planejamento de práticas pedagógicas significativas implica olhar para a criança, fornecendo os meios para que ela se aproprie dos bens culturais produzidos pela humanidade, favorecendo o desenvolvimento da autonomia, da criatividade e da solidariedade, particularmente pela via da brincadeira (BUSS-SIMÃO, 2006; VIEIRA; MEDEIROS, 2007).

No tocante ao trabalho pedagógico com bebês e crianças bem pequenas ${ }^{2}$, sinaliza-se a importância de um projeto educativo que os pense no coletivo da creche, enquanto protagonistas do processo educativo, valorizando seus modos de se comunicar, interagir e compreender o mundo (ROCHA; GONÇALVEZ, 2015; SIMIANO, 2016). De modo semelhante, ao investigar a prática da EF na EI de zero a três anos, Gaspar, Richter e Vaz (2015) discutem a relevância de se perceber o corpo para além das suas dimensões anátomo-fisiológicas, considerando suas diferentes formas de expressão e primando pela escuta, pelo diálogo e pela qualidade das relações entre adultos e crianças e entre estas e seus pares. 
Frente ao exposto, corrobora-se o fato de que a docência com crianças de zero a três anos guarda especificidades, ao mesmo tempo em que impõe desafios no momento de se pensar a EF direcionada à EI. Afinal: Como organizar o tempo da educação física visando contrapor o modelo disciplinar? Como atuar em parceria com os demais profissionais da instituição? Como se comunicar e interagir com aqueles que ainda não falam ou falam pouco? Esses e outros questionamentos permearam a prática de ensino realizada no estágio curricular supervisionado (ECS), servindo de motivação para a elaboração deste relato que objetiva refletir sobre a docência com um grupo de bebês, a partir do olhar da EF inserida na EI da rede municipal de Florianópolis/SC.

\section{Conhecendo e interagindo com os bebês}

A experiência docente ocorreu no ECS na EI, realizado na $5^{a}$ fase do curso de licenciatura em EF de uma universidade pública de Santa Catarina. Participaram do processo dois acadêmicos e a professora orientadora, além dos profissionais vinculados à instituição campo de estágio, sendo um professor de EF, a professora regente e a professora auxiliar de sala.

O estágio foi realizado em um Neim localizado na região continental da cidade. $\mathrm{O}$ espaço físico é amplo e arejado, possuindo um parque com área arborizada, uma pequena quadra, quatro salas de aulas com banheiro infantil, secretaria, biblioteca, sala de professores, depósito de materiais de EF, sala da supervisão, banheiro coletivo, cozinha, além de um hall espaçoso, equipado com televisão, mesas, cadeiras, tapetes e almofadas que possibilitam a realização de diversas atividades em diferentes momentos da rotina da instituição.

No período de realização do estágio atuavam na instituição professoras e auxiliares de sala, auxiliares de serviços gerais, cozinheira, diretora e supervisora. Também havia um professor de EF responsável por supervisionar as ações desenvolvidas em quatro grupos matutinos e quatro vespertinos, com crianças entre um e cinco anos e 11 meses.

As 90 horas do estágio eram distribuídas entre encontros na universidade e permanência no campo de estágio, sendo o último dividido em dois momentos: observação e intervenção. A observação destina-se ao levantamento das informações sobre as crianças, os professores e os projetos pedagógicos, além das rotinas de sala e da unidade educativa. Já a intervenção é quando os estagiários assumem a condução das atividades planejadas durante a observação. As experiências aqui relatadas aconteceram no período vespertino, com um grupo que atendia 15 bebês, entre um e dois anos de idade.

O fato das observações acontecerem no início do ano letivo, ainda no período de adaptação dos bebês à instituição, exigiu um esforço em relação à inserção na rotina e interação com o grupo, de modo que se familiarizassem com as novas presenças naquele contexto. Inicialmente, a chegada em sala era motivo de estranhamento, de modo que 
alguns bebês não se aproximavam, buscando a atenção das professoras e do professor de EF, como alguém que lhes era familiar. Com encontros mais frequentes, as crianças se mostravam confortáveis, a confiança aumentava e, também, os "convites" para brincar. A convivência nos diferentes momentos da rotina apresentou-se como elemento facilitador no estabelecimento do vínculo com os bebês, extrapolando os momentos de EF e atentando para a articulação entre o cuidar e o educar (VIEIRA; BEZERRA, 2012).

No tempo de permanência na instituição, foi possível acompanhar as atividades que compunham a rotina dos bebês, como a acolhida e saída, o descanso, troca de fraldas, alimentação, além de choros, brincadeiras e disputas por brinquedos. Isso permitiu conhecer melhor cada um deles, servindo de subsídio para organização e planejamento das intervenções.

Ao longo da experiência, três aspectos foram marcantes e ilustram as especificidades da ação docente junto aos bebês: o lugar da EF na EI; a organização dos espaços e materiais; e a relação com a linguagem, os quais são abordados a seguir.

\section{A docência com os bebês: ampliando o olhar}

O ponto de partida desta análise refere-se ao lugar da EF na EI, em que se assume o cuidar e o educar como dimensões indissociáveis (FLORIANÓPOLIS, 2010). Com base nesse princípio, a EF distancia-se dos modelos tradicionais de atendimento à infância pautados na transmissão de conhecimentos que fixam o tempo curricular das aulas, fragmentando conteúdos e desconsiderando ritmos, interesses, desejos e necessidades das crianças (GASPAR; RICHTER; VAZ, 2015).

Nessa perspectiva, a EF inserida na EI deve integrar o projeto político pedagógico (PPP) de cada unidade, permitindo que as atividades, os dias e os tempos sejam organizados de modo diferenciado, atendendo a especificidade da faixa etária e os princípios pedagógicos desta etapa educacional (FLORIANÓPOLIS, 2007). Sobre isso, Gaspar, Richter e Vaz (2015) explicam que não há uma orientação única relativa à organização do tempo de EF; a inserção desse componente curricular nas instituições de EI em Florianópolis é determinada coletivamente, pelos professores de cada unidade.

Tal aspecto foi observado nesse Neim, no qual a EF é oferecida em dois encontros semanais, sendo um de 60 e outro de 75 minutos. Esse horário ampliado conta com a mediação do professor de EF em momentos da rotina das crianças, envolvendo alimentação, higiene, sono e demais atividades organizadas pelas professoras de sala, além da tematização das práticas da cultura corporal (SOARES et. al., 1992). Com isso, percebeu-se que a EF pertence a um contexto maior, composto por horários e atividades relacionadas aos cuidados com os bebês e que precisariam ser incorporados nas intervenções, de modo a atender as demandas de uma prática que supere a fragmentação dos 'tempos' destinados a cada atividade. 
Para Raupp e Neiverth (2011), a legislação vigente destaca o direito da criança à brincadeira, à segurança, à imaginação e à higiene, de modo que não cabe pensar a EF distanciada desta perspectiva. Para além dos momentos de EF, buscou-se conhecer e interagir com cada bebê, identificando suas formas de se movimentar, se expressar e interagir com objetos, com outras crianças e com os adultos naquele novo espaço, por se tratar da primeira experiência fora do seio familiar.

Ainda segundo as autoras, a chegada de bebês e crianças bem pequenas a um espaço coletivo é um momento delicado para elas, para as famílias e para a instituição. Portanto, ao longo desse processo procurou-se, juntamente com as professoras de sala e com o professor de EF, organizar propostas no intuito de colaborar com a rotina do grupo. Em relação aos bebês que ainda não se locomoviam sozinhos, buscou-se uma aproximação, chamando-os para as situações de movimento organizadas na sala, enquanto aqueles que já demonstravam mais autonomia, eram estimulados a realizar ações para o desenvolvimento de habilidades motoras, explorando os espaços e materiais organizados. Com isso, as professoras de sala tinham condições de oferecer atendimento mais individualizado àqueles que choravam ou que não demonstravam interesse em participar das brincadeiras, bem como despertar o interesse daqueles que, ao verem os colegas, também queriam se envolver na proposta.

Autores como Ayoub (2001), Vieira e Bezerra (2012), Gaspar, Richter e Vaz (2015), corroboram que a EF nas instituições de EI não deve ocorrer isoladamente, mas como parte do currículo e integrada ao projeto educativo da instituição, não cabendo, assim, a racionalização do conteúdo, que leva à fragmentação do conhecimento e da própria criança. Nesse sentido, emergiu o desafio de pensar a EF para além dos momentos formais a ela destinados, evidenciando a necessidade de realizar um trabalho integrado com as professoras de sala e com o professor de EF, contando com a colaboração desses profissionais na elaboração das propostas, condução, avaliação e replanejamento das aulas.

A importância dessa parceria ficou clara em uma das intervenções, nascida a partir do registro da pouca interação dos bebês com outros ambientes, que não a sala de referência. Optou-se por proporcionar uma vivência no hall da instituição. Nesse dia, foi organizado um circuito com atividades de equilíbrio, subidas e descidas, ultrapassagem de obstáculos, transporte e encaixe de objetos. O desafio estava na organização do ambiente e das próprias crianças naquele espaço, pois não se tinha previsão da reação das crianças, nem a possibilidade de atender a todas naquele ambiente. Mas, com a colaboração da professora regente, que acompanhava os bebês que queriam retornar à sala, ou que estavam dormindo, bem como do professor de EF, que auxiliava na condução das brincadeiras com o restante do grupo, a proposta teve êxito. Para Souza e Rojas (2010), a atuação do professor de EF deve ser pensada de forma interdependente e interdisciplinar, preservando as especificidades de seus saberes e integrando-os às demais áreas do conhecimento, favorecendo, assim, não só o desenvolvimento das crianças, mas também a interação humana dentro da unidade. 
Essa iniciativa rendeu situações como idas ao parquinho, apreciação de peças de teatro, banda de música, festa junina, entre outras, que favoreceram a interação dos bebês com outras crianças e profissionais da instituição. Os episódios permitiram várias experimentações, sempre respeitando os que se sentiam pouco à vontade com o barulho ou com os outros adultos. Segundo Vieira e Bezerra (2012), ampliar a presença e a participação dos bebês nos espaços da instituição representa uma oportunidade de reconhecimento deles como parte integrante da creche, contribuindo para a construção do sentimento de pertencimento à unidade.

Além das interações, essa vivência foi um momento de descoberta da necessidade de reconsiderar as propostas a partir das manifestações dos bebês no que se refere à ocupação do tempo ao longo da rotina definida pela instituição, incluídos os momentos de EF. Logo, cabe ao professor o cuidado de não engessar a prática, mantendo um planejamento flexível, que considere, para além do tempo do relógio, os modos como os elementos da cultura corporal são experienciados.

Outro aspecto que se destacou nessa experiência refere-se à organização dos espaços e materiais, enquanto elemento central na docência com os bebês. Zabalza (2009) afirma a importância de organizar os espaços de modo que se constituam num ambiente rico e estimulante da aprendizagem e do desenvolvimento infantil, oferecendo situações em que as crianças possam manusear brinquedos e objetos diversos, correr, subir, descer, reconhecer amigos e a si mesmas.

Constatou-se, ao longo das intervenções, que a organização do espaço na EI precisa ser algo dinâmico que favoreça as brincadeiras, novas experiências e as interações com os pares. Logo, a experimentação de espaços externos e internos, brinquedos que possibilitem as mais diversas atividades motoras e diferentes formas de mediação, que transitam entre atividades dirigidas e momentos de brincadeiras livres, estão intimamente ligados ao estímulo do desenvolvimento (RODRIGUES; SARAIVA; GABBARD, 2005).

Assim como descrito por Rocha, Girardi e Buss-Simão (2014), um aspecto que chamou atenção durante as observações foi que nem todos os bebês se envolviam ao mesmo tempo nas situações propostas pela professora regente. Enquanto um grupo parava para ouvir uma história, ou uma música, outros demonstravam interesse pelos brinquedos que estavam na sala. Outros, ainda, choravam, pois estavam com sono, de modo que as professoras mantinham um espaço organizado com colchões ou bebê conforto, para aqueles que desejassem dormir.

De modo semelhante, as situações propostas pelo professor de EF nem sempre envolviam todo o grupo, sendo uma preocupação respeitar o tempo e interesse de cada um, sem, contudo, deixar de incentivar a participação e envolvimento nas brincadeiras. Isso era evidente nos momentos em que o bebê, mesmo convidado a participar, não se envolvia diretamente na brincadeira proposta. 
Tal situação criou um dilema: de um lado, a necessidade de respeitar o tempo de cada bebê; de outro, desenvolver uma prática pedagógica que considerasse a especificidade da EF na EI, sem que isso implicasse a uniformização ou padronização do que era proposto. Frente a esse cenário, foram priorizadas situações próximas àquelas que os bebês já estavam familiarizados, sem muitas modificações. Conforme o vínculo entre os estagiários e os bebês se estreitava, e eles se mostravam mais confortáveis, optou-se por instituir mudanças no planejamento, reorganizando os espaços e materiais que seriam empregados nos momentos de EF, de modo a potencializar as interações, a exploração, a expressão e o envolvimento dos bebês nas situações propostas (SIMIANO, 2016).

Uma alteração importante foi reuni-los no tapete da sala de aula, sentados em roda, onde conversava-se sobre o que seria feito naquele dia. Nas primeiras tentativas, nem todos se envolveram. Após algumas intervenções, alguns bebês já se organizavam no tapete, aguardando o momento da roda inicial, que passou a fazer parte da rotina. A incorporação da roda de conversa, mostrou-se como uma prática de grande relevância na promoção de saberes, além de um momento de partilha, criação e acolhida (VARGAS; PEREIRA; MOTTA, 2016).

Essa alteração possibilitou a criação de uma rotina, vinculada à presença dos estagiários, que facilitou a aproximação com os bebês, bem como o envolvimento nas brincadeiras, o que foi aumentando gradualmente. Uma demonstração de como as modificações e/ou inserções foram feitas, envolveu a exploração de blocos de espuma com formas variadas (círculo, cubos, triângulos, cilindros etc.), disponíveis na instituição e que foram utilizados de diferentes maneiras ao longo das aulas. Inicialmente, os bebês ficaram livres para manusear o material como quisessem. Na sequência, os blocos foram dispostos no chão, formando um caminho para que as crianças andassem sobre eles, equilibrando-se. Nesse momento, a atenção era individualizada a cada criança que mostrasse interesse em participar. Por fim, os bebês foram estimulados a montar uma torre com os blocos de espuma, que eram empilhados uns sobre os outros. Assim, cada um trazia um bloco para acrescentar à pilha, até que a torre, finalmente, caísse. Esse movimento de carregar e empilhar blocos de espuma, para depois vê-los cair, provocava grande satisfação nos bebês, que, aos poucos, foram se envolvendo na brincadeira.

No encontro seguinte, visando ampliar a vivência anterior, foi proposto um circuito motor, com cadeiras enfileiradas, formando uma ponte. A estratégia foi retomada em outros momentos, utilizando almofadas para criar instabilidade, rampas, túneis, colchonetes, obstáculos e marcações no chão, a fim de desafiar corporalmente o grupo e oferecer novos estímulos. Em todas essas ocasiões, o auxílio da professora regente e do professor de EF permitiu imprimir dinamicidade à brincadeira e oferecer atenção individualizada, observando o quesito segurança. As propostas devem ser convidativas, assegurando a integridade física e psicológica das crianças. Para tanto, o professor precisa analisar previamente as atividades, espaços e materiais, além de considerar os 
sinais dados pelas crianças durante a exploração desses elementos, promovendo adequações (ROCHA; GIRARDI; BUSS-SIMÃO, 2014; FLORIANÓPOLIS, 2016).

Para favorecer a experiência tátil aos bebês, foram propostas brincadeiras e a exploração de objetos diversos, como copos plásticos, balões, canudos, caixas de papelão etc. Em um primeiro momento, os bebês tinham a oportunidade de explorar os objetos. $\mathrm{Na}$ sequência, as situações oportunizavam a manipulação e exploração dos objetos, observando suas características (cores, tamanho, formas e texturas), por meio de brincadeiras de encaixar, agrupar, empilhar, transportar, lançar, dentre outras.

Ao longo das intervenções, percebeu-se que manipular objetos trazia grande satisfação aos bebês. $\mathrm{O}$ fato incentivou a criação da proposta embrulho misterioso, em que foram levados diversos pacotes para serem manipulados e desembrulhados, revelando o segredo neles. Em um dos pacotes foi colocado um brinquedo de fazer bolhas de sabão. Prontamente, os bebês se sentiram atraídos e se envolveram na brincadeira. Inicialmente, eles deveriam apenas estourar as bolhas. Com o tempo, passaram a querer fazer as bolhas também. Nesse momento, tentou-se atender aqueles que pediam para assoprar e fazer a bolha, atividade que se mostrou muito prazerosa e atrativa para o grupo.

Observando as ações das crianças, viu-se que é preciso cuidado em relação ao material oferecido. Embora sejam capazes de descobrir por si, elas precisam de implementos adequados para suportar suas manipulações e curiosidade. Para a realização de movimentos locomotores e axiais, os materiais devem ser maiores e mais rígidos, podendo ser menores para os manipulativos (FERNANDES et. al., 2016; RANGEL; DARIDO, 2010).

O envolvimento dos bebês na exploração dos objetos e a descoberta de diversas formas de brincar demonstram a importância da organização e modificação dos elementos do espaço, oportunizando novas experiências de aprendizagem e desenvolvimento das habilidades motoras, cognitivas e sociais (ROCHA; GIRARDI; BUSS-SIMÃO, 2014). Logo, pensar o espaço nas intervenções ao grupo de bebês implicou considerar suas relações com os materiais, com as situações de movimento e com os outros, imprimindo mudanças, tanto no ambiente como na atividade e em seus modos de realização. Por essa via, o espaço, para além do aspecto físico e geográfico, representa um elemento pedagógico no qual significados são produzidos pelos sujeitos que ali se encontram (SIMIANO, 2016).

As vivências acima descritas, foram perpassadas pela questão da linguagem, que se colocou como um verdadeiro desafio, visto que muitos bebês ainda não possuíam a oralidade desenvolvida. Os bebês e as crianças bem pequenas se expressam para além da linguagem oral, apresentando mais fortemente outras formas de comunicação, como olhares, gestos, balbucios, choros ou gargalhadas, para indicar desejos, anseios, frustrações, interesses e necessidades (SCHMITT, 2008). Assim, foi necessário aprender a se comunicar com os bebês e pensar em como propor algo para um grupo que tem outras formas de se manifestar, que não prioritariamente por meio de palavras. 
O dilema da comunicação revelou a importância de considerar outras formas de se relacionar com o conhecimento, como o gesto (GASPAR; RICHTER; VAZ, 2015). Assim, ao propor uma brincadeira, além de verbalizar, buscou-se demonstrar as ações. Cada novo movimento era acompanhado de uma fala sobre ele, indicando, assim, o que se esperava que os bebês fizessem, estimulando também o desenvolvimento da escuta e da oralidade. Outra estratégia era solicitar auxílio de um deles na experimentação dos movimentos, o que servia de incentivo à participação dos mais retraídos ou inseguros. Numa atividade de equilíbrio, por exemplo, como na ponte de cadeiras, quando um bebê se aproximava, demonstrando curiosidade com a proposta, era oferecida ajuda na transposição do obstáculo e logo os outros, ao perceberem a movimentação, juntavam-se ao grupo.

Era preciso atentar para aquilo que as crianças manifestavam durante as brincadeiras, buscando compreender a forma de comunicação e os encaminhamentos dados por elas, os quais, muitas vezes, fugiam ao planejamento. O plano precisou ser reorientado, a partir da compreensão dos bebês acerca das situações propostas, no sentido de ampliar a relação com os objetos e com os pares.

Utilizou-se, novamente, da estratégia de promover uma livre exploração inicial dos materiais, seguida de encaminhamentos sobre os objetivos traçados, para captar a diversidade de interesses, saberes e significados produzidos pelos bebês, traduzindo-os para a prática, na apresentação de um novo objeto, como nos jogos de encaixe. Enquanto eles brincavam, as características dos materiais eram enunciadas e questionadas, instigando a curiosidade sobre as formas, texturas, tamanho, cores e peso dos objetos. Com isso, era possível (re)conhecer e incorporar no planejamento das atividades os modos de interação e de comunicação dos bebês. Nesse sentido, na organização e reorganização dos espaços e materiais, juntamente com os ajustes linguísticos, não se faziam exigências a um fim, mas buscava-se ampliar e diversificar as experiências dos bebês, a fim de estimular a criatividade, a autonomia e a curiosidade (GASPAR; RICHTER; VAZ, 2015).

Para facilitar a tentativa de diálogo, ao chegar à sala, o método era uma aproximação cautelosa. Sentava-se no chão, aguardando que as crianças iniciassem o contato. A partir daí, conseguia-se abertura para apresentação das propostas. Na roda inicial estabeleciam-se os combinados, enquanto na roda final falava-se sobre o que havia sido realizado na ocasião, se haviam gostado ou não das vivências. Nesses momentos, tentava-se traduzir em palavras os gestos, olhares e sorrisos que eles manifestavam.

Percebeu-se, com isso, que a comunicação vai além do que é falado e que, na condição de professores, precisamos escutar com atenção o que os bebês e as crianças bem pequenas têm a dizer, ainda que não o façam por meio de palavras. É importante, assim, ampliar o olhar sobre seus gestos e manifestações, os quais surgem carregados de sentidos, interesses e necessidades, refletindo suas experiências e vivências, que não podem ser ignoradas no processo pedagógico. 


\section{Por novos "olhares"}

Nesse relato foi descrita uma experiência de prática docente com um grupo de bebês no ECS da EF, o que contribuiu, sobremaneira, à superação de limitações decorrentes da falta de experiência, bem como para a ampliação da visão sobre os bebês enquanto sujeitos de direitos, detentores de saberes e de necessidades que devem ser considerados no planejamento e desenvolvimento da prática docente.

O estágio representou uma oportunidade ímpar de aproximação da realidade da EI, cujo desafio foi realizar um trabalho conjunto em que a EF não se limita ao momento da aula apenas, integrando-se aos demais tempos e espaços na rotina da instituição. A seleção e organização dos espaços e materiais se mostrou um ponto positivo dessa experiência, uma vez que o rearranjo destes proporcionou desafios e interações, ampliando o repertório de vivências motoras, cognitivas e sociais, constituindo-se, assim, em lugar para os bebês usufruírem a sua infância. A questão da linguagem, por sua vez, exigiu estabelecer outras relações com o conhecimento, tornando a comunicação por meio do corpo, por via gestual, na centralidade do processo educativo.

Definir conteúdos e estratégias, de forma que sejam significativos para os bebês, não é tarefa simples, de modo que o acolhimento, o diálogo e o apoio por parte dos professores da instituição foram fundamentais, possibilitando novas experimentações tanto para as crianças como para aqueles que chegam à instituição na condição de estagiários. Por fim, espera-se que esse relato contribua para ampliar a compreensão por parte do futuro professor acerca das especificidades da docência na EI, motivando acadêmicos e professores a refletir e relatar suas práticas nesse contexto.

Recebido em 06/06/2020. Aprovado em 18/08/2020.

\section{Notas}

1 Na Rede Municipal de Florianópolis existem dois tipos de instituições de Educação Infantil: creches organizadas que atendem crianças em tempo integral; e Núcleos de Educação Infantil Municipal (NEIM), que oferecem atendimento parcial, matutino ou vespertino.

2 Os termos utilizados consideram a seguinte faixa etária: bebês até 1 ano e 11 meses; crianças bem pequenas - 2 anos e 11 meses a 3 anos e 11 meses; e crianças pequenas - entre 3 anos e 11 meses a 5 anos e 11 meses (FLORIANÓPOLIS, 2012). 


\section{Referências}

AYOUB, E. Reflexões sobre Educação Física na Educação Infantil. Revista Paulista de Educação Física, São Paulo, Supl. 4, p. 53-60, dez. 2001.

BRASIL. Constituição da República Federativa do Brasil. Brasília, 1988. Disponível em: http://www. planalto.gov.br/ccivil_03/Constituicao/Constituiçao.htm. Acesso em: 1 jun. 2020.

BRASIL. Lei n⿳0 9394, de 20 de dezembro de 1996. Estabelece as diretrizes e bases da educação nacional. Disponível em: http://www.planalto.gov.br/ccivil_03/leis/19394.htm. Acesso em: 1 jun. 2020.

BUSS-SIMÃO, M. Educação física na educação infantil: refletindo sobre a "hora da educação física". Motrivivência, Florianópolis, Ano XVII, n. 25, p. 163-173, dez., 2006.

FERNANDES, K. L. S. et. al. O trabalho com espaço e forma na educação infantil: Experiências em colaboração. Revista Eletrônica de Educação, São Carlos, v. 10, n. 3, p. 433-445, nov. 2016.

FLORIANÓPOLIS. A Educação Física na Educação Infantil da Rede Municipal de Ensino de Florianópolis. Prefeitura Municipal. Florianópolis: Secretaria Municipal de Educação, 2016.

FLORIANÓPOLIS. Diretrizes educacionais pedagógicas para educação infantil. Prefeitura Municipal de Florianópolis. Secretaria Municipal de Educação. Florianópolis: Prelo Gráfica \& Editora Ltda., 2010.

FLORIANÓPOLIS. Orientações Curriculares para a Educação Infantil Municipal. Florianópolis: Prefeitura Municipal de Florianópolis, Secretaria Municipal de Educação, 2012.

FLORIANÓPOLIS. Portaria n⿳0 036/07 de 9 de abril de 2007. Altera a portaria $\mathrm{n}^{\mathrm{0}}$ 067/06, que estabeleceu os critérios de distribuição das vagas para os cargos integrantes dos grupos docente e especialistas em assuntos educacionais do quadro do magistério nas unidades educativas. Diário Oficial do Município de Florianópolis. Florianópolis, SC, 2007.

GASPAR, B. S.; RICHTER, A. C.; VAZ, A. F. Das práticas pedagógicas para a Educação Física Infantil de 0 a 3 anos no município de Florianópolis. Currículo sem Fronteiras, [online], v. 15, n. 1, p. 231-251, jan./ abr. 2015.

KUHLMANN JUNIOR, M. Histórias da educação infantil brasileira. Revista Brasileira de Educação, Rio de Janeiro, n. 14, p. 5-18, maio/ago. 2000.

NOGUEIRA, G. M.; VIEIRA, S. R. Contribuições da pedagogia da infância para a articulação entre educação infantil e anos iniciais do ensino fundamental. Revista Linhas, Florianópolis, v. 14, n. 26, p. 265-292, jan./jun. 2013.

RANGEL, I. C. A.; DARIDO, S. C. Educação Física na Infância. Rio de Janeiro: Guanabara Koogan, 2010. (Série: Educação Física no Ensino Superior).

RAUPP, M. D.; NEIVERTH, T. Retratos da infância: o conhecimento e o lúdico. Revista Retratos da Escola, Brasília, v. 5, n. 9, p. 291-307, jul./dez. 2011.

ROCHA, E. A. C.; GIRARDI, L. R.; BUSS-SIMÃO, M. Experimentando a docência com bebês no estágio supervisionado: organizando espaços, brincadeiras e interações. Zero-a-Seis, Florianópolis, v. 16, n. 30, p. 290-303, jul./dez. 2014.

ROCHA, E. A. C.; GONÇALVES, F. A produção científica sobre a educação de bebês e crianças pequenas no contexto coletivo da creche. Poiésis, Niterói, v. 9, n. 15, p. 44-62, jan.jun. 2015. 
RODRIGUES, L. P.; SARAIVA, L.; GABBARD, C. Development and construct validation of an inventory for assessing the home environment for motor development. Research Quarterly for Exercise and Sport, v. 76, n. 2, p. 140-148, jun., 2005.

SAYÃO, D. T. Educação Física na pré-escola: da especialização disciplinar à possibilidade de trabalho pedagógico integrado. Dissertação (Mestrado em Educação) - Programa de Pós-graduação em Educação, Universidade Federal de Santa Catarina, Florianópolis, 1996.

SCHMITT, R. V. “Mas eu não falo a língua deles!": as relações sociais de bebês num contexto de Educação Infantil. Dissertação (Mestrado em Educação) - Programa de Pós-graduação em Educação, Universidade Federal de Santa Catarina, Florianópolis, 2008.

SIMIANO, L. P. Transver o mundo: um olhar sobre o lugar dos bebês no espaço da creche. Zero a Seis, Florianópolis, v. 18, n. 33 p. 22-31, jan.jjun. 2016.

SOARES, C. L. et. al. Metodologia do ensino da Educação Física. São Paulo: Cortez, 1992. (Coleção Magistério $2^{\circ}$ grau. Série formação do professor).

SOUZA, R. S. E.; ROJAS, J. Educação Física e interdisciplinaridade na Educação de Infância. Motrivivência, Florianópolis, Ano XX, n. 31, p. 207-222, jul. 2010.

VARGAS, V. A.; PEREIRA, V. A.; MOTTA, M. R. A. Reflexões sobre as rodas de conversa na Educação Infantil. Zero-a-Seis, Florianópolis, v. 18, n. 33, p. 122-143, mar. 2016.

VIEIRA, C. L. N.; BEZERRA, M. S. H. Compartilhando propostas pedagógicas na Educação Infantil: a Educação Física e uma experiência com bebês. Zero-a-Seis, Florianópolis, v. 14, n. 26, p. 116-128, jul./dez., 2012.

VIEIRA, C. L. N.; MEDEIROS, F. E. A produção do conhecimento em educação física na educação infantil no contexto histórico da rede municipal de ensino de Florianópolis (SC): levantamento dos eixos teórico-metodológicos e epistemológicos em documentos da Rede. Motrivivência, Florianópolis, v. 19, n 29, p. 55-74, dez. 2007.

ZABALZA, M. Qualidade em Educação Infantil. Porto Alegre: Artmed, 2009. 